\title{
Influence of the X-Chromosome on Neuroanatomy: Evidence from Turner and Klinefelter Syndromes
}

\author{
David S. Hong, ${ }^{1}$ Fumiko Hoeft, ${ }^{1,2}$ Matthew J. Marzelli, ${ }^{1,3}$ Jean-Francois Lepage, ${ }^{1}$ David Roeltgen, ${ }^{4}$ Judith Ross, ${ }^{4}$ \\ and Allan L. Reiss ${ }^{1,5,6}$ \\ ${ }^{1}$ Center for Interdisciplinary Brain Sciences Research, Stanford, California 94305, 2Department of Psychiatry, University of California, San Francisco, \\ California 94143, ${ }^{3}$ Department of Bioengineering, Stanford University, Stanford, California 94305, ${ }^{4}$ Division of Pediatric Endocrinology, Thomas Jefferson \\ University, Philadelphia, Pennsylvania 19107, and ${ }^{5}$ Department of Psychiatry and Behavioral Sciences and ${ }^{6}$ Department of Radiology, Stanford University, \\ Stanford, California 94305
}

Studies of sex effects on neurodevelopment have traditionally focused on animal models investigating hormonal influences on brain anatomy. However, more recent evidence suggests that sex chromosomes may also have direct upstream effects that act independently of hormones. Sex chromosome aneuploidies provide ideal models to examine this framework in humans, including Turner syndrome (TS), where females are missing one X-chromosome (45X), and Klinefelter syndrome (KS), where males have an additional X-chromosome (47XXY). As these disorders essentially represent copy number variants of the sex chromosomes, investigation of brain structure across these disorders allows us to determine whether sex chromosome gene dosage effects exist. We used voxel-based morphometry to investigate this hypothesis in a large sample of children in early puberty, to compare regional gray matter volumes among individuals with one (45X), two (typically developing 46XX females and 46XY males), and three (47XXY) sex chromosomes. Between-group contrasts of TS and KS groups relative to respective sex-matched controls demonstrated highly convergent patterns of volumetric differences with the presence of an additional sex chromosome being associated with relatively decreased parieto-occipital gray matter volume and relatively increased temporo-insular gray matter volumes. Furthermore, $z$-score map comparisons between TS and KS cohorts also suggested that this effect occurs in a linear dose-dependent fashion. We infer that sex chromosome gene expression directly influences brain structure in children during early stages of puberty, extending our understanding of genotype-phenotype mechanisms underlying sex differences in the brain.

Key words: Klinefelter syndrome; neuroimaging; sex chromosome; Turner syndrome

\section{Introduction}

Sex differences in physiological and pathophysiological domains have been reported extensively in the literature (Wilson et al., 1981; Mendelsohn and Karas, 2005; Siegel et al., 2010). While controversial, differences have also been identified in socioemotional and cognitive abilities, including aggression (Archer, 2004), visuospatial ability (Voyer et al., 1995; Rilea et al., 2004), and verbal fluency (Halpern, 1992). Although socio-cultural influences certainly play an integral role, there is also evidence that underlying neurobiological mechanisms may drive these differ-

\footnotetext{
Received July 1, 2013; revised Jan. 7, 2014; accepted Jan. 15, 2014.

Author contributions: D.S.H., D.R., J.R., and A.L.R. designed research; D.S.H., M.J.M., J.-F.L., D.R., J.R., and A.L.R. performed research; D.S.H., F.H., and M.J.M. analyzed data; D.S.H., F.H., J.-F.L., and A.L.R. wrote the paper.

This work is supported by funding support from the National Institute of Mental Health (NIMH; MH050047), National Institute of Child Health and Human Development (HD049653), National Institute of Neurological Disorders and Stroke (NS050597), and the Chain of Love Foundation. D.S.H. is also supported by funding from the NIMH (MH092170). J.-F.L. is supported by a postdoctoral fellowship from the Canadian Institutes of Health Research. We also gratefully acknowledge the assistance of Daniel Bryant, Karen Kowal, Bria Dunkin, Kristen Sheau, and Lindsay Chromik. We extend our sincere gratitude to the individuals and families who participated in this study.

The authors declare no competing financial interests.

Correspondence should be addressed to Dr. David S. Hong, 401 Quarry Road MC5795, Stanford, CA 94305. E-mail: dshong@stanford.edu.

DOI:10.1523/JNEUROSCI.2790-13.2014

Copyright $\odot 2014$ the authors $\quad 0270-6474 / 14 / 343509-08 \$ 15.00 / 0$
}

ences, including findings that parietal regions associated with visuospatial cognition differ between males and females, as do other anatomical structures related to emotion processing, such as the amygdala, hippocampus, and orbitofrontal cortex (Gur et al., 2002; Neufang et al., 2009; Weickert et al., 2009; Hänggi et al., 2010). Furthermore, previous literature suggests that sex differences in brain development may differentially impact cognitive ability. This includes findings that global and spatial performance correlate with segmented gray and white matter volumes in both sexes, though verbal performance is correlated with cranial volume only in females (Gur et al., 1999). Improved understanding of sex-related variation in neuroanatomy is critical, as it may also provide insight into clinically significant sex differences in childhood neuropsychiatric disorders (Yoshimasu et al., 2010; Manning et al., 2011).

Sex chromosome aneuploidies such as Turner syndrome (TS) and Klinefelter syndrome (KS) represent compelling models in which to investigate these complex relationships, as they essentially represent copy number variants of the X-chromosome. TS occurs exclusively in females and results from the loss of one $\mathrm{X}$-chromosome (45X), while KS affects males and results from an additional X-chromosome (47XXY). Both are common disorders (TS: 1/2500; KS: 1/1000) and are associated with character- 
istic phenotypes that broadly impact endocrinological and other physiological domains (Baena et al., 2004; Lanfranco et al., 2004). In addition, TS and KS have each been associated with distinct cognitive-behavioral profiles. While overall intelligence is generally average in both disorders, females with TS often demonstrate intact verbal skills and impairments in visuospatial skills, executive functions, and social cognition (Hong et al., 2009), in contrast to males with KS who often have difficulties with executive function and language, while visuospatial skills are relatively preserved (Boada et al., 2009). Neurobiological underpinnings for these differences have begun to emerge in independent studies, including findings of aberrant cortical gray matter volume in parieto-occipital, orbitofrontal, and superior temporal regions in TS compared with female controls (Molko et al., 2004; Marzelli et al., 2011), and gray matter reductions in frontal and temporal regions in KS compared with male controls (Giedd et al., 2007; Bryant et al., 2011). These qualitative comparisons suggest a distinct signature of sex chromosome and hormone effects on brain development occurring in a complementary/contrasting pattern relative to $\mathrm{X}$-chromosome dosage.

Interestingly, there has been no comparison of brain structure between TS and KS, particularly in children. Investigating this issue would elucidate dosage effects of the X-chromosome on sex differences in brain structure and cognitive-behavioral function during early pubertal development, a relatively quiescent period of sex hormone influence. We used voxel-based morphometry (VBM) to directly compare neuroanatomy in early pubertal girls with TS and boys with KS relative to typically developing (TD) female and male controls. Our goal was to elucidate the impact of $\mathrm{X}$-chromosome dosage effects on brain structure in TS and KS and provide further elaboration of the contribution of sex chromosome gene products to sex-specific cortical development.

\section{Materials and Methods}

Participants. A total of 129 participants were included in this study, ranging in age from 6 to 12 years. Subjects were recruited and scanned at two academic centers: at Stanford University (SU) 42 early pubertal girls with TS $(9.6 \pm 1.6)$ were referred from pediatric endocrinologists, the national Turner Syndrome Society network, and the Center for Interdisciplinary Brain Sciences Research website and 30 TD age-matched female controls $(9.1 \pm 1.9)$ were recruited through local parent organizations, advertisements, and female siblings of TS participants (four sister-pairs comprised of one sister with TS and one TD sister). At Thomas Jefferson University (TJU), 31 males with KS $(9.4 \pm 2.0)$ were self-referred or referred from pediatric endocrinologists, and 26 age-matched TD male controls (10.6 \pm 1.6$)$ were recruited using Internet notices and referrals from other participating families. Subjects at each site were part of larger, unrelated studies on TS and KS, respectively, and independent studies of these populations have been reported previously (Bryant et al., 2011; Marzelli et al., 2011).

All TS (45X) and KS (47XXY) diagnoses were confirmed by standard karyotype and participants were only included in the study if karyotype results ( $\geq 20$ cells) were completely non-mosaic. None of the TS and KS participants had initiated systemic hormone replacement therapy (estrogen for TS and testosterone for KS; one TS subject used topical estrogen cream for labial lesions). Thirty-six subjects with TS were treated with growth hormone. All TD participants were in good overall medical health. None of the participants reported any previous or current neurological or psychiatric diagnoses, or were taking psychotropic medication at the time of assessment. Furthermore, all participants were screened at time of entry into the study for pubertal status: female subjects with Tanner scores 1 or 2 for female breast and pubic hair development were included, as were any male subjects with testicular volume $>4 \mathrm{ml}$, a threshold falling between male Tanner stages 1 and 2. Males with KS were also assessed on height and weight, given their increased risk for obesity and metabolic syndrome. BMI-for-age percentiles were calculated for both male cohorts using a standard BMI calculator (http://apps.nccd. cdc.gov/dnpabmi). Informed consent and assent were obtained from all parents and participants, and study protocols were approved by the Stanford University School of Medicine and Thomas Jefferson University Institutional Review Boards.

Cognitive and psychological assessments. At the SU site, the Wechsler Intelligence Scale for Children Fourth Edition (WISC-IV) was administered, providing a total Full-scale IQ (FSIQ) and index scores for Verbal Comprehension (VCI), Perceptual Reasoning (PRI), Working Memory Index (WMI), and Processing Speed (PSI). At the TJU site, the Differential Ability Scales were used, providing index scores of General Conceptual Ability (GCA), Verbal Ability, Nonverbal Reasoning, and Spatial Ability. Both tests measure intellectual ability and are normed to a mean of 100 with an SD of 15. Direct comparisons of previous versions of these assessments (WISC-III and the DAS) have demonstrated significant correlations between constructs of general intelligence (FSIQ in the WISC-IV and the General Conceptual Ability score for the DAS-II) and verbal ability (VCI and Verbal Ability score, respectively) and only moderate correlations in nonverbal ability domain scores (Dumont et al., 1996). For comparable indices between assessments, such as FSIQ/GCA and VIQ/Verbal Ability, between-group differences were tested using ANOVA, with post hoc pairwise comparisons conducted using Tukey's HSD test, $p$ values $<.05$ were considered significant. For the remaining subscales, differences between TS and TD females, and between KS and TD males, were analyzed with independent $t$ tests, with a significance threshold of $p<0.05$. Analyses of BMI-for-age percentiles found that neither male cohort fell within the "overweight" category (KS mean $\mathrm{BMI} \%=56.02 \%$, TD males mean $\mathrm{BMI} \%=63.11)$, nor were mean $\mathrm{BMI}$ measures significantly different between groups $(p=0.30)$.

Magnetic resonance imaging data acquisition. At SU, magnetic resonance imaging (MRI) was performed in the Lucas Center for Imaging at Stanford University using a 3.0 T GE Signa whole-body scanner (GE Healthcare Systems) with a standard head coil. High-resolution anatomical brain images using a T1-weighted fast spoiled gradient echo pulse sequence were acquired ( 124 coronal slices, $1.5 \mathrm{~mm}$ thickness, $\mathrm{TR}=6.40$ $\mathrm{ms}, \mathrm{TE}=2.10 \mathrm{~ms}$, $\mathrm{TI}=300 \mathrm{~ms}$, flip angle $=15^{\circ}, 0.86 \times 0.86 \times 1.5$ $\mathrm{mm}^{3}$ ). At TJU, MRI scanning was performed on a Philips 3.0 T Achieva whole-body scanner (Philips Medical Systems) using an eight-channel SENSE head coil. Images were obtained using a high-resolution, T1weighted fast gradient echo sequence ( 160 slices, $1.0 \mathrm{~mm}$ thickness, $\mathrm{TR}=$ $25 \mathrm{~ms}, \mathrm{TE}=2.3 \mathrm{~ms}$, flip angle $=30^{\circ}$, voxel size $\left.=0.96 \times 0.96 \times 1 \mathrm{~mm}^{3}\right)$.

MRI data analysis. All images were converted to NIFTI format and manually aligned to the AC-PC axis, followed by visual inspection for significant motion artifacts. Using the New Segment utility as implemented in SPM8 (www.fil.ion.ucl.ac.uk/spm/software/spm8/), images were then bias corrected and segmented with default tissue probability maps for gray matter (GM), white matter (WM), and CSF. This pipeline also performs integrated spatial normalization and modulation of images, with nonlinear regularization using a standard ICBM template. The resulting modulated, warped images for each tissue class were then spatially smoothed using a standard Gaussian full-width at half-maximum kernel of $8 \mathrm{~mm}$, and a threshold mask was applied to exclude background voxels. Global brain volume differences between groups were analyzed using an ANCOVA with age as a covariate, with a statistical threshold of $p<0.05$ being considered significant. In the first stage of the analysis, a full factorial model was used to test our a priori hypothesis that $\mathrm{X}$-chromosome complement influences brain volume by creating a oneway ANOVA with group as the between-subject factor and age, total GM volume and FSIQ as covariates, centered around the group mean. Specific differences between groups were assessed using $t$ tests on a voxel-byvoxel basis, and results were considered significant at a cluster threshold of $p<0.05$ FWE-corrected, voxel-height $p<0.001$ uncorrected. To clarify overlapping X-chromosome dosage effects, we conducted a conjunction analysis using statistical images in the between-group contrasts (Nichols et al., 2005) to assess the intersection of volumetric differences associated with a relative decrease $(\mathrm{X}>\mathrm{XX}$ and $\mathrm{XY}>\mathrm{XXY})$ or a relative increase in $\mathrm{X}$-chromosome dosage $(\mathrm{XX}>\mathrm{X}$ and $\mathrm{XXY}>\mathrm{XY})$. Again, clusters were considered significant at $p<0.05$ FWE-corrected, voxelheight $p<0.001$ uncorrected. 
Table 1. Demographic and cognitive assessments

\begin{tabular}{|c|c|c|c|c|c|c|}
\hline & $\mathrm{TS}(n=42)$ & $X X(n=30)$ & $\mathrm{KS}(n=31)$ & $X Y(n=26)$ & ANOVA $p$ value & Significant post hoc comparisons \\
\hline Age & $9.1(1.9)$ & $9.5(2.0)$ & $9.7(1.7)$ & $10.6(1.6)$ & 0.017 & $\mathrm{TS}<\mathrm{XY}$ \\
\hline Global IQ ${ }^{a}$ & $92.4(12.7)$ & $117.03(11.7)$ & $90.5(14.4)$ & $109.6(13.2)$ & $<0.001$ & $\mathrm{TS}=\mathrm{KS}<\mathrm{XX}=\mathrm{XY}$ \\
\hline Verbal Ability $^{b}$ & $102.8(11.6)$ & $116.7(15.1)$ & $88.3(13.0)$ & $111.2(14.0)$ & $<0.001$ & $\mathrm{KS}<\mathrm{TS}, \mathrm{XX}, \mathrm{XY} ; \mathrm{TS}<\mathrm{XX}$ \\
\hline WISC-IV PRI & $93.3(13.5)$ & $116.8(10.6)$ & - & - & $<0.001$ & - \\
\hline WISC-IV WMI & $85.3(18.4)$ & $104.5(12.1)$ & - & - & $<0.001$ & - \\
\hline WISC-IV PSI & $87.6(19.6)$ & $110.8(12.4)$ & - & - & $<0.001$ & - \\
\hline DAS Nonverbal Reasoning & - & - & $95.1(15.5)$ & $108.9(12.2)$ & 0.001 & - \\
\hline DAS Spatial Ability & - & - & $91.2(13.9)$ & $103.9(15.6)$ & 0.002 & - \\
\hline TGMV $^{c}$ & $689.4(56.6)$ & $688.2(58.9)$ & $718.1(67.0)$ & $743.4(58.7)$ & 0.001 & $\mathrm{TS}=\mathrm{XX}<\mathrm{XY}$ \\
\hline TWMV $^{d}$ & $449.1(38.7)$ & 450.4 (41.4) & $482.1(46.2)$ & $504.7(47.1)$ & $<0.001$ & $\mathrm{TS}=\mathrm{XX}<\mathrm{KS}=\mathrm{XY}$ \\
\hline $\mathrm{TCSF}^{e}$ & $275.0(25.1)$ & $280.1(29.0)$ & $267.5(30.2)$ & $269.2(31.9)$ & 0.310 & - \\
\hline
\end{tabular}

ANOVA for age, and global and verbal intellectual ability were tested between all groups. Post hoc Tukey's HSD results demonstrated significant differences. $T$ test comparisons of WISC-IV WMI and PSI scores were also conducted between TS and TD females (XX), and DAS Nonverbal Reasoning and Spatial Ability were compared between KS and TD males (XY). Mean score and SD on each measure for, respectively, TS, XX, KS, and XY groups. ${ }^{a}$ Comprised of FSIQ score for TS and $\mathrm{XX}$, General Conceptual Ability score for KS and XY. ${ }^{b}$ Comprised of VCl for TS and XX, and Verbal Cluster score for KS and XY. ${ }^{\circ}$ Total gray matter volume (in ml). ${ }^{d}$ Total white matter volume (in ml). ${ }^{e}$ Total CSF volume (in ml).

Given that subjects' group membership was completely collinear with scan site as TS and TD females were scanned at SU, while KS and TD males were scanned at TJU, direct comparisons between these groups were not feasible. Therefore, we calculated individual $z$-score maps for each TS and KS subject, such that a $z$-score was calculated by subtracting the value at each voxel against the mean voxel value of the respective control group (TD females for TS and TD males for XY) and dividing by the mean control sample deviation. Calculating $z$-score maps in the TS group isolates variation in cortical volume specifically related to absence of X-chromosome genes. Similarly, $z$-scores for XXY against the XY sample mean generally quantifies volumetric differences resulting from additional X-chromosome gene expression, while putatively canceling out the effect of the Y-chromosome shared across KS and male TD controls. Individual $z$-score maps were then used in a voxelwise whole-brain analysis examining GM differences between TS and KS cohorts using two-sample $t$ tests, with age, FSIQ, and TGMV entered as covariates, centered around the overall group mean. Clusters were considered significant at a voxel height of $p<0.001$ uncorrected and a cluster threshold of $p<0.05$ FWE-corrected. Nonstationary cluster extent correction was used for all analyses, as implemented in the VBM5.1 toolbox (dbm.neuro.uni-jena.de/vbm/).

\section{Results}

\section{Demographic and cognitive data}

Groups differed with regard to age (group factor: $F=3.54, \mathrm{p}=$ 0.017 with post hoc pairwise comparisons using Tukey's HSD showing that the TD male group was older than the TS group $(p=0.009)$. Overall intellectual abilities also differed between groups for total score (comprised of FSIQ/GCA; $F=32.61, p<$ 0.001 ), post hoc Tukey's HSD comparisons demonstrated no differences between KS and TS groups, while both groups had lower scores than both TD groups. There were no differences in FSIQ between TD females and males. For verbal ability (comprised of VIQ/Verbal Ability; $F=26.24, p<0.001$ ) the KS group had lower scores than all the other groups (all $p<0.001$ ) and the TS group had lower scores than the TD female group $(p<0.001)$, but did not differ significantly from the TD male group, and there were no significant differences between TD females and males. $T$ tests demonstrated that the TS cohort performed significantly lower than TD females on the PRI $(p<0.001)$, Working Memory Index (WMI; $p<0.001)$, and PSI $(p<0.001)$, and the KS group performed lower than TD males on Nonverbal Reasoning $(p<$ $0.001)$ and Spatial Ability $(p<0.001)$. Demographic and cognitive scores are summarized in Table 1.

\section{Whole-brain VBM analyses}

ANCOVAs of uncorrected total raw volumes corrected for age demonstrated significant between-group differences on mea- sures of TGMV $(F=5.69, p=0.001)$ and TWMV $(F=11.80$, $p<0.001)$, but not on total CSF $(p=0.310)$. Post hoc comparisons showed that both TS and TD females had reduced TGMV compared with TD males, and reduced TWMV compared with both KS and TD males (Table 1).

\section{Between-group $t$ test comparisons}

Whole-brain pairwise comparisons controlling for age, FSIQ, and TGMV were also conducted to examine differences between groups.

\section{TS versus TD females}

Girls with TS demonstrated increased GMV in bilateral cerebellum, large bilateral clusters encompassing amygdala-hippocampal complexes, and adjacent parahippocampal gyri, and extending superiorly into bilateral insula and superior temporal gyri, with left GMV differences relatively greater than right. Increased GMV was also found in bilateral superior frontal regions in dorsomedial prefrontal cortex and the left frontal superior orbital gyrus. In contrast, the TD girls demonstrated increased GMV bilaterally in a large region encompassing bilateral precuneus, superior and inferior parietal regions, and extending anteriorly into bilateral postcentral gyri. Clusters were also present in bilateral calcarine regions and the left lingual gyrus (Table 2, Fig. 1).

\section{KS versus TD males}

GM comparisons showed that the KS group had increased GMV in bilateral clusters encompassing postcentral and precentral gyri, as well as a large midline cluster encompassing bilateral cuneus and precuneus. Additionally, there was a small cluster in the right inferior parietal lobule, approximating the angular gyrus and in the left middle frontal gyrus. TD males demonstrated increased GMV in bilateral amygdala-hippocampal regions with small extensions into the parahippocampal gyri, as well as large clusters in bilateral insula, a small cluster encompassing a region around the hypothalamus, and a small cluster spanning the midline bilateral supplementary motor area (Table 2, Fig. 1).

\section{Conjunction analyses}

Analyses were calculated to assess the overlap in brain regions that varied with respect to relative $\mathrm{X}$-chromosome dosage. Conjunctional comparison using between-group contrasts of TS $>$ $\mathrm{XX}$ and XY $>$ XXY demonstrated significantly increased GMV in bilateral amygdala-hippocampal complexes, extending to the parahippocampus on the right, as well as clusters in bilateral insula (left $>$ right). Conjunction analysis assessing overlap be- 


\begin{tabular}{|c|c|c|c|c|c|c|c|}
\hline & \multirow[b]{2}{*}{ Brodmann area } & \multicolumn{3}{|c|}{ Peak voxel (Talairach coordinates) } & \multirow[b]{2}{*}{$T$} & \multirow[b]{2}{*}{ Cluster $p$ value (FWE-corrected) } & \multirow[b]{2}{*}{ Extent } \\
\hline & & $x$ & $y$ & $z$ & & & \\
\hline \multicolumn{8}{|l|}{$T$ test comparisons } \\
\hline \multicolumn{8}{|l|}{ TS $>$ TD females } \\
\hline L hippocampus & - & -34 & -20 & -18 & 7.35 & $<0.001$ & 7354 \\
\hline L frontal superior orbital & 11 & -18 & 37 & -12 & 6.50 & 0.041 & 481 \\
\hline R hippocampus & 20 & 37 & -7 & -22 & 6.33 & $<0.001$ & 3976 \\
\hline L cerebellum & - & -33 & -74 & -24 & 5.41 & $<0.001$ & 1633 \\
\hline R frontal superior & 8 & 19 & 29 & 51 & 4.95 & $<0.001$ & 1959 \\
\hline R cerebellum & 19 & 34 & -73 & -13 & 4.72 & 0.005 & 855 \\
\hline L frontal superior & 8 & -19 & 34 & 43 & 4.59 & 0.044 & 469 \\
\hline \multicolumn{8}{|l|}{ TD females $>$ TS } \\
\hline L precuneus & 7 & -9 & -47 & 58 & 6.43 & $<0.001$ & 11348 \\
\hline R calcarine & 31 & 21 & -63 & 14 & 5.40 & 0.001 & 1157 \\
\hline L lingual & 19 & -25 & -70 & -2 & 5.12 & 0.036 & 502 \\
\hline L cuneus & 31 & -16 & -64 & 24 & 4.58 & 0.041 & 483 \\
\hline \multicolumn{8}{|l|}{$\mathrm{KS}>\mathrm{TD}$ males } \\
\hline L postcentral & 3 & -39 & -27 & 62 & 6.97 & $<0.001$ & 2802 \\
\hline R postcentral & 6 & 59 & -8 & 45 & 5.80 & $<0.001$ & 3524 \\
\hline L precuneus & 7 & -9 & -66 & 46 & 5.41 & $<0.001$ & 5915 \\
\hline L middle frontal & 47 & -45 & 42 & -5 & 4.97 & 0.037 & 497 \\
\hline R inferior parietal & 39 & 36 & -62 & 38 & 4.68 & 0.025 & 561 \\
\hline \multicolumn{8}{|l|}{ TD males $>$ KS } \\
\hline L hippocampus & - & -16 & -12 & -8 & 5.46 & 0.004 & 896 \\
\hline R hippocampus & - & 24 & -11 & -10 & 5.07 & 0.001 & 1149 \\
\hline L insula & 13 & -37 & 10 & -9 & 4.89 & 0.002 & 1085 \\
\hline R insula & 13 & 42 & -1 & 0 & 4.75 & $<0.001$ & 1574 \\
\hline R medial globus pallidus & - & 7 & 0 & -4 & 4.74 & 0.028 & 539 \\
\hline L superior frontal & 8 & -3 & 23 & 49 & 4.35 & 0.025 & 558 \\
\hline \multicolumn{8}{|l|}{ Z-score map comparisons } \\
\hline \multicolumn{8}{|l|}{$\mathrm{TS}>\mathrm{KS}$} \\
\hline L hippocampus & - & -32 & -22 & -16 & 17.61 & $<0.001$ & 158378 \\
\hline R precuneus & 31 & 28 & -75 & 24 & 6.50 & 0.001 & 1501 \\
\hline L cuneus & 19 & -22 & -82 & 31 & 6.34 & 0.034 & 552 \\
\hline \multicolumn{8}{|l|}{$\mathrm{KS}>\mathrm{TS}$} \\
\hline L postcentral & 2 & -21 & -35 & 62 & 10.19 & $<0.001$ & 39609 \\
\hline R middle occipital & 19 & 34 & -77 & 3 & 7.46 & 0.011 & 768 \\
\hline
\end{tabular}

tween XX $>$ TS and XXY $>$ XY contrasts showed small clusters in the bilateral cuneus, right precuneus, and right angular gyrus, as well as bilateral postcentral gyri (left $>$ right).

\section{$Z$-score comparisons between TS and KS groups}

Regional GM comparisons controlling for age, FSIQ, and TGMV, demonstrated that girls with TS had significantly greater GMV relative to KS bilaterally in the cerebellum, middle occipital gyri, posterior cingulate, fusiform, superior temporal gyri, insula, hippocampi extending to amygdalae, caudate, and superior and middle frontal gyri. The KS group demonstrated increased GMV relative to the TS group in a large bilateral cluster encompassing cuneus, precuneus, superior and inferior parietal, postcentral and precentral regions, as well as a small cluster in the right middle occipital gyrus (Table 2, Fig. 2).

\section{Discussion}

Extant studies to date indicate that X-chromosome aneuploidy results in characteristic cognitive-behavioral and neuroanatomical features. Here, we present the first study to directly examine the effects of X-chromosome dosage on brain structure in early pubertal children, through the inclusion of cohorts with a deficient (TS) or supplementary (KS) complement of X-chromosomes. Using voxelwise comparisons, we demonstrate significant differences in regional brain volumes, including relative GM increases in temporal regions associated with having one
$\mathrm{X}$-chromosome, contrasting with relative increases in parietooccipital regions associated with having two X-chromosomes.

Previous studies have separately examined regional volume differences in TS and KS (Patwardhan et al., 2000; Kesler et al., 2004; Molko et al., 2004; Giedd et al., 2007), including earlier independent findings on these cohorts from our group (Bryant et al., 2011; Marzelli et al., 2011). Not surprisingly, our findings are highly consistent with these studies and provide further evidence for neuroanatomical correlates of an X-chromosome gene dosage effect. This includes consistent evidence that an additional $\mathrm{X}$-chromosome is associated with increased GMV in precentral, postcentral, and posterior parieto-occipital regions, while lack of an X-chromosome is associated with increased GMV in the insula and superior temporal gyrus (STG). The anatomical localization of these findings is also expected, given the specific cognitivebehavioral domains that are typically affected in these disorders. For example, parieto-occipital GMV is correlated with visuospatial ability (Sack et al., 2007) and volumetric decreases in this region have been linked to impaired visuospatial skills in TS (Bray et al., 2013), while both this region and associated cognitive ability are relatively preserved in individuals with KS (Giedd et al., 2007). Conversely, STG and hippocampal volumes, which are associated with verbal memory and auditory processing (Karlsgodt et al., 2005; DeWitt and Rauschecker, 2012), are consistently found to be decreased in KS (Shen et al., 2004; DeLisi et al., 2005), while verbal skills and temporal lobe volume are relatively in- 
8

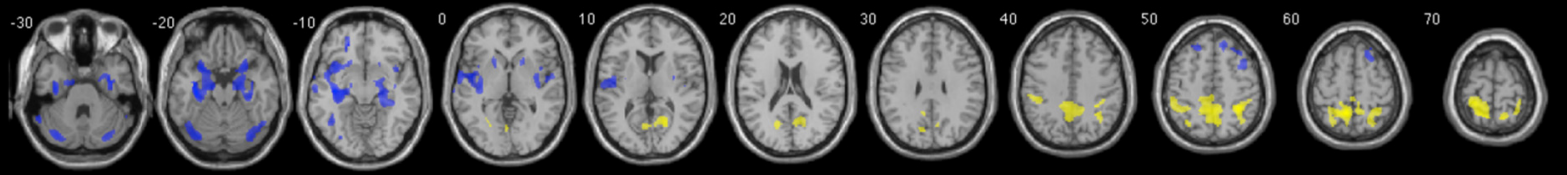

$X O$ vs. $X X$

b
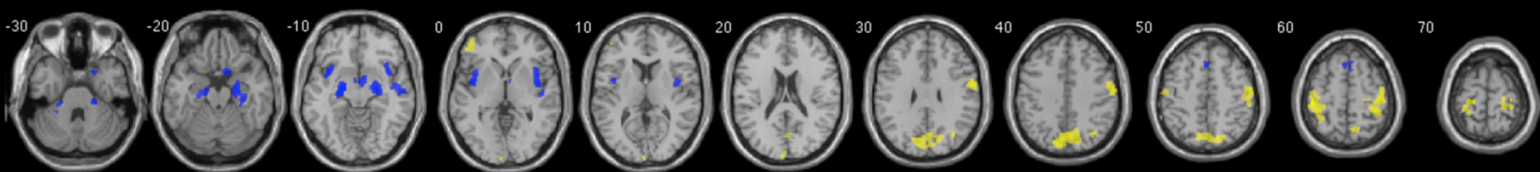

$X Y$ vs. $X X Y$

C
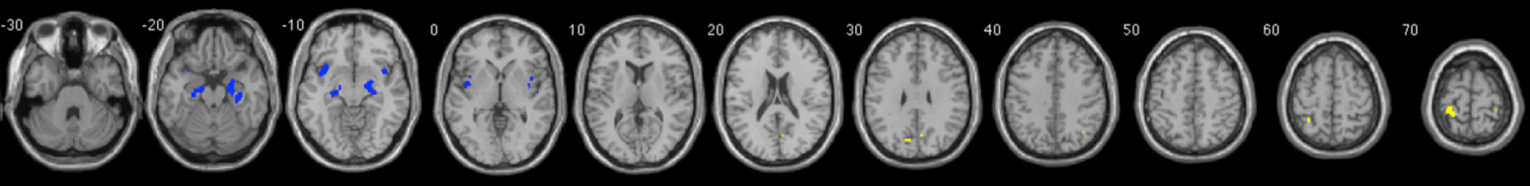

Figure 1. Between-group comparisons for TS and KS cohorts relative to respective sex-matched controls, demonstrating GMV differences associated with X-chromosome complement. $\boldsymbol{a}$, GMV differences between TS and TD females: blue, TS females > TD females; yellow, TD females > TS females. $\boldsymbol{b}$, GMV differences between KS and TD males: blue, KS males > TD males; yellow, TD males $>$ KS males. c, Conjunction analyses demonstrating intersection between contrasts illustrated in $\boldsymbol{a}$ and $\boldsymbol{b}$ : blue, overlap between TS $>$ TD females and TD males $>$ KS males contrasts; yellow, overlap in clusters between TD females $>$ TS and KS males $>$ TD males contrasts. For all analyses, clusters are considered significant at $p<0.05 \mathrm{FWE}$, voxel-height $p<0.001$, and include TGMV, age, and FSIQ as covariates.

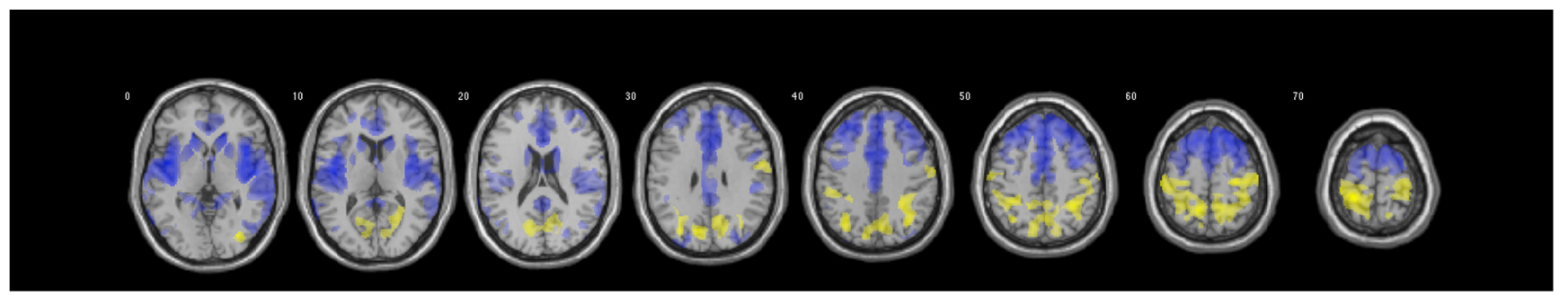

Figure 2. Ttest comparison between TS and KS groups usingz-score maps relative to respective sex-matched controls. Increased GMV noted for the TS group in frontotemporal regions (blue, TS females $>$ KS males) and for the KS group in parietal regions (yellow, KS males $>$ TS females). Clusters are considered significant at $p<0.05 \mathrm{FWE}$, voxel-height $p<0.001$. Covariates include total GMV, age, and FSIQ.

creased in TS (Temple and Carney, 1996; Rae et al., 2004). In support of this hypothesis, our cognitive-behavioral data also demonstrate that males in the KS group lag behind all other cohorts in verbal abilities, including the TS group. Together, the consistency of these differences suggests that these neuroanatomical and cognitive findings may not be disorder specific per se, but may arise from shared underlying mechanisms acting in a dose-dependent fashion.

Previous literature has delineated several frameworks for understanding sex influences on neuroanatomy and behavior
(McCarthy and Arnold, 2011; Ngun et al., 2011). The majority of attention has focused on "masculinizing" effects of gonadal sex hormones on brain structure, primarily during prenatal and adolescent periods (Berenbaum and Beltz, 2011; Lombardo et al., 2012). It would be compelling to attribute our findings to this hypothesis given that girls with TS have significantly decreased sex hormone production due to premature ovarian failure occurring as early as the 15th week of gestation (Modi et al., 2003), a critical time period in the organization of neural structures. In contrast, the hormone status of boys with KS is less clear-while it 
has been suggested that they have physiologically normal levels of sex steroids until the onset of puberty (Wikström et al., 2006), it is possible they have earlier signs of testosterone deficiency that are not detectable with sensitivity of current assays (Ross et al., 2005). Furthermore, recent studies indicate that sex hormone levels vary considerably even between TD girls and boys in the prepubertal period, with females having higher levels of estrogen and androgens compared with males (Courant et al., 2010). This phenomenon likely arises from adrenal androgen production, which typically increases before the onset of gonadal puberty and starts at a younger age in females relative to males. Notably, girls with TS have been shown to demonstrate earlier onset of adrenarche (Martin et al., 2004), in contrast to boys with KS where aberrant adrenarchal trajectories have not been identified. However, the possible modulatory role of adrenal androgens on prenatal sex chromosome and gonadal hormone effects should also be considered, particularly as adrenal androgen levels have been correlated with dynamic changes in cortical thickness of the cingulate cortex and occipital pole even in prepubertal stages (Nguyen et al., 2013). Together, these factors present a complex scenario where TD girls have slightly higher levels of estrogen and testosterone relative to boys with KS and TD males, and girls with TS likely have substantially lower levels of sex steroids overall. While sex hormone differences may explain part of the variation in neuroanatomy between groups, this line of reasoning is insufficient to explain why the TS cohort who are putatively sex hormone-deficient relative to control females and the KS cohort who presumably have equivalent or slightly decreased sex hormone levels relative to male peers show opposing directions of brain volume differences. Instead, our results are consistent with a growing literature demonstrating that upstream genetic effects of sex chromosomes act independently of downstream hormonal factors to result in sex differences (Davies and Wilkinson, 2006; McCarthy and Arnold, 2011).

In fact, aberrant patterns of gene expression from the pseudoautosomal regions (PARs) of the sex chromosomes may explain this dose-dependent effect on neurodevelopment. As opposed to other X-chromosome genes that are silenced by X-inactivation in TD females, genes in the PAR have homologs on both $\mathrm{X}$ - and Y-chromosomes. Therefore, expression of genes in this region would be expected to be haploinsufficient in TS and overexpressed in KS. Findings on other physiological aspects of TS and KS also support this hypothesis, including evidence that increased copy numbers of the SHOX gene in PAR1 have been directly correlated to height (Rao et al., 1997). Girls with TS are putatively haplosufficient in SHOX gene expression due to the absence of an X-chromosome and are typically short statured, whereas boys with KS (who have three copies of the SHOX gene) are generally taller than male peers. Though the genetic basis for the neurocognitive phenotype in TS and KS has yet to be identified, several studies have isolated regions on the PAR1 of the $\mathrm{X}$-chromosome where dysregulated gene expression profiles may impact cognition and neuroanatomy in a similar fashion. For example, Ross et al. (2000) found that that deletions distal to Xp22.3 correlate with visuospatial deficits in TS, while overexpression of other genes in the same region is associated with verbal deficits in KS (Vawter et al., 2007). Remarkably, our data demonstrate that neuroanatomical regions associated with these cognitive domains show a similar relationship, in which an increased number of sex chromosomes (XX $>$ TS and KS $>\mathrm{XY}$ ) correlates with increases in GMV in the parieto-occipital regions, and relative decreases in the temporo-insular region. The highly convergent anatomical overlap strongly supports a dose-depen- dent framework for sex chromosome effects, especially when considering that these results are derived from independent samples. Furthermore, findings in these two regions using $z$-score maps suggest that sex chromosome effects in these regions are not only dose dependent, but additive, as regional differences between cohorts with one versus three sex chromosomes are even more pronounced than comparisons between cohorts with one versus two sex chromosomes. This also suggests that effects may not be specific to the X-chromosome per se, but are the result of overall sex chromosome dosage, which would be consistent with previous studies of sex chromosome aneuploidies in adults (Lentini et al., 2013).

While the findings presented here appear consistent with a pattern associated with sex chromosome complement, it is important to keep in mind that other factors, including epigenetic and hormonal effects, interact with genetic mechanisms to influence the anatomy and function of specific brain regions. For example, we found that global GMV and WMV were larger in both male cohorts overall. While these differences may be affected by dissimilar scanners at the two sites, they are also consistent with previous literature showing that male brains are consistently larger than female brains (Goldstein et al., 2001; Lenroot et al., 2007). A possible interpretation may be that global brain volumes are driven by genetic influences of the Y-chromosome or male-specific prenatal exposure to testosterone and therefore would only impact the KS and TD male cohorts, while variation in regional volumes may, at least in part, be driven by differential gene expression patterns from the X-chromosome. Another important factor to consider is the potential effect of activational changes induced by hormone surges during adrenarche and puberty. While our findings suggest the existence of stable gene dosage effects presumably established during the prenatal period, it is also likely that developmental changes driven by adrenal androgens in late childhood and by gonadal hormones during adolescence may further amplify or decrease regional between-group differences resulting from sex chromosome dosage effects. In fact, we attempted to investigate this issue further by conducting an exploratory analysis stratifying individuals into a young cohort (age $\leq 9$ years) and an old cohort (age $\geq 10$ years). Results show more extensive volumetric differences in the younger cohort for the TS $>$ KS contrast, encompassing the cingulate cortex and superior frontal regions, suggesting the presence of developmental differences even between early and late childhood. It is feasible that these age-related changes may in fact correspond to the onset of adrenarche in this age range, an issue that should be studied with larger sample sizes and in greater detail in the sex chromosome aneuploidy population. This premise may also partly explain some of the differences noted in our results in young children relative to studies involving adult subjects where sex chromosome effects localize to the precentral gyrus (Lentini et al., 2013). Indeed, the influence of sex hormones on brain structures during puberty has been well documented in typical development (Peper et al., 2009; Bramen et al., 2012), but not in the sex chromosome aneuploidy literature, underscoring the importance of further research in this area. While we limited inclusion of our study to children in Tanner stages 1 or 2 for both sexes, greater discrimination of pubertal status in future studies may elucidate fine-grained developmental changes occurring even at early stages of puberty.

It is also important to note that the results from our study are potentially confounded by differences in assessment and scanning protocols at each site. Specifically, the two sites used different cognitive tests, thresholds for pubertal status, and scanner equipment to assess between-group differences. While our findings are consistent with previous literature examining such between-group differences and are in line with our a priori 
hypothesis-driven predictions, future studies using identical assessment and scanning protocols across all cohorts should be conducted to avoid these confounds. Another important point to consider for the TS cohort in our study is the possible confound of growth hormone influence. As short stature is a core feature of the TS phenotype, growth hormone supplementation is frequently indicated for girls with this condition. The impact of growth hormone on brain development has yet to be fully elucidated and further investigation of this issue is needed in prospective studies both in TS and typical development. In fact, future work in general is needed to more clearly dissect the complex interaction of X-and Y-chromosome complement and sex hormone status on neurodevelopment, particularly during the dynamic period of adolescence. Indeed, a better understanding of sex chromosome dosage effects may provide critical insights into neural processes underlying neuropsychiatric disorders of childhood, many of which have significant sex differences in onset and symptomatology, including attention-deficit hyperactivity disorder (ADHD), autism, and learning disorders (Barbaresi et al., 2005; Bauermeister et al., 2007; Yoshimasu et al., 2010; BaronCohen et al., 2011). In fact, both girls with TS and boys with KS have increased problems with inattention and a higher prevalence of ADHD (Mazzocco, 2006; Russell et al., 2006; Bruining et al., 2009; Tartaglia et al., 2012), and 79\% of girls with TS meet diagnostic criteria for Mathematics Learning Disorder (Murphy et al., 2006) while $50-75 \%$ of boys with KS demonstrate a reading disability (Bender et al., 1986; Graham et al., 1988), suggesting a shared pathophysiological link between sex chromosome aneuploidy and childhood psychiatric disorders with distinct sex differences.

In the present study, we demonstrate significant differences in brain structure between individuals with TS and KS, and begin to elucidate a neuroanatomical profile related to sex chromosome complement. In a larger scope, these findings suggest that sex chromosome gene expression may influence neurodevelopment in a dose-dependent fashion, with contrasting effects on neuroanatomy and cognition as revealed in TS and KS. Further studies are needed in this critical area of research to further disentangle the interactions of sex chromosomes and hormones on neurodevelopment. Prospective studies examining longitudinal trajectories of sex hormone and chromosome influences across dynamic periods of brain development and gene expression analyses of the $\mathrm{X}$-chromosome may provide further insight into the genotypephenotype relationships that are observed here.

\section{Notes}

Supplemental material for this article is available at http://cibsr.stanford. edu/news/publications_supplemental_influencex.html. An exploratory analysis was conducted with cohorts stratified by age. This material has not been peer reviewed.

\section{References}

Archer J (2004) Sex differences in aggression in real-world settings: a metaanalytic review. Rev Gen Psychol 8:291-322. CrossRef

Baena N, De Vigan C, Cariati E, Clementi M, Stoll C, Caballín MR, Guitart M (2004) Turner syndrome: evaluation of prenatal diagnosis in 19 European registries. Am J Med Genet A 129A:16-20. CrossRef Medline

Barbaresi WJ, Katusic SK, Colligan RC, Weaver AL, Jacobsen SJ (2005) Math learning disorder: incidence in a population-based birth cohort, 1976-82, Rochester, Minn. Ambul Pediatr 5:281-289. CrossRef Medline

Baron-Cohen S, Lombardo MV, Auyeung B, Ashwin E, Chakrabarti B, Knickmeyer R (2011) Why are autism spectrum conditions more prevalent in males? PLoS Biol 9:e1001081. CrossRef Medline

Bauermeister JJ, Shrout PE, Chávez L, Rubio-Stipec M, Ramírez R, Padilla L, Anderson A, García P, Canino G (2007) ADHD and gender: are risks and sequela of ADHD the same for boys and girls? J Child Psychol Psychiatry 48:831-839. CrossRef Medline

Bender BG, Puck MH, Salbenblatt JA, Robinson A (1986) Dyslexia in 47, XXY boys identified at birth. Behav Genet 16:343-354. CrossRef Medline

Berenbaum SA, Beltz AM (2011) Sexual differentiation of human behavior: effects of prenatal and pubertal organizational hormones. Front Neuroendocrinol 32:183-200. CrossRef Medline

Boada R, Janusz J, Hutaff-Lee C, Tartaglia N (2009) The cognitive phenotype in Klinefelter syndrome: a review of the literature including genetic and hormonal factors. Dev Disabil Res Rev 15:284-294. CrossRef Medline

Bramen JE, Hranilovich JA, Dahl RE, Chen J, Rosso C, Forbes EE, Dinov ID, Worthman CM, Sowell ER (2012) Sex matters during adolescence: testosterone-related cortical thickness maturation differs between boys and girls. PLoS One 7:e33850. CrossRef Medline

Bray S, Hoeft F, Hong DS, Reiss AL (2013) Aberrant functional network recruitment of posterior parietal cortex in turner syndrome. Hum Brain Mapp 34:3117-3128. CrossRef Medline

Bruining H, Swaab H, Kas M, van Engeland H (2009) Psychiatric characteristics in a self-selected sample of boys with Klinefelter syndrome. Pediatrics 123:e865-870. CrossRef Medline

Bryant DM, Hoeft F, Lai S, Lackey J, Roeltgen D, Ross J, Reiss AL (2011) Neuroanatomical phenotype of Klinefelter syndrome in childhood: a voxel-based morphometry study. J Neurosci 31:6654-6660. CrossRef Medline

Courant F, Aksglaede L, Antignac JP, Monteau F, Sorensen K, Andersson AM, Skakkebaek NE, Juul A, Bizec BL (2010) Assessment of circulating sex steroid levels in prepubertal and pubertal boys and girls by a novel ultrasensitive gas chromatography-tandem mass spectrometry method. J Clin Endocrinol Metab 95:82-92. CrossRef Medline

Davies W, Wilkinson LS (2006) It is not all hormones: alternative explanations for sexual differentiation of the brain. Brain Res 1126:36-45. CrossRef Medline

DeLisi LE, Maurizio AM, Svetina C, Ardekani B, Szulc K, Nierenberg J, Leonard J, Harvey PD (2005) Klinefelter's syndrome (XXY) as a genetic model for psychotic disorders. Am J Med Genet B Neuropsychiatr Genet 135B:15-23. CrossRef Medline

DeWitt I, Rauschecker JP (2012) Phoneme and word recognition in the auditory ventral stream. Proc Natl Acad Sci U S A 109:E505-514. CrossRef Medline

Dumont R, Cruse CL, Price L, Whelley P (1996) The relationship between the differential ability scales (DAS) and the Wechsler intelligence scale for children-Third edition (WISC-III) for students with learning disabilities. Psychol Schools 33:203-209. CrossRef

Giedd JN, Clasen LS, Wallace GL, Lenroot RK, Lerch JP, Wells EM, Blumenthal JD, Nelson JE, Tossell JW, Stayer C, Evans AC, Samango-Sprouse CA (2007) XXY (Klinefelter syndrome): a pediatric quantitative brain magnetic resonance imaging case-control study. Pediatrics 119:e232-240. CrossRef Medline

Goldstein JM, Seidman LJ, Horton NJ, Makris N, Kennedy DN, Caviness VS Jr, Faraone SV, Tsuang MT (2001) Normal sexual dimorphism of the adult human brain assessed by in vivo magnetic resonance imaging. Cereb Cortex 11:490-497. CrossRef Medline

Graham JM Jr, Bashir AS, Stark RE, Silbert A, Walzer S (1988) Oral and written language abilities of XXY boys: implications for anticipatory guidance. Pediatrics 81:795-806. Medline

Gur RC, Turetsky BI, Matsui M, Yan M, Bilker W, Hughett P, Gur RE (1999) Sex differences in brain gray and white matter in healthy young adults: correlations with cognitive performance. J Neurosci 19:4065-4072. Medline

Gur RC, Gunning-Dixon F, Bilker WB, Gur RE (2002) Sex differences in temporo-limbic and frontal brain volumes of healthy adults. Cereb Cortex 12:998-1003. CrossRef Medline

Halpern DF (1992) Sex differences in cognitive abilities, Ed 2. Hillsdale, NJ: Lawrence Erlbaum Associates.

Hänggi J, Buchmann A, Mondadori CR, Henke K, Jäncke L, Hock C (2010) Sexual dimorphism in the parietal substrate associated with visuospatial cognition independent of general intelligence. J Cogn Neurosci 22:139_ 155. CrossRef Medline

Hong D, Scaletta Kent J, Kesler S (2009) Cognitive profile of Turner syndrome. Dev Disabil Res Rev 15:270-278. CrossRef Medline

Karlsgodt KH, Shirinyan D, van Erp TG, Cohen MS, Cannon TD (2005) 
Hippocampal activations during encoding and retrieval in a verbal working memory paradigm. Neuroimage 25:1224-1231. CrossRef Medline

Kesler SR, Garrett A, Bender B, Yankowitz J, Zeng SM, Reiss AL (2004) Amygdala and hippocampal volumes in Turner syndrome: a highresolution MRI study of X-monosomy. Neuropsychologia 42:1971-1978. CrossRef Medline

Lanfranco F, Kamischke A, Zitzmann M, Nieschlag E (2004) Klinefelter's syndrome. Lancet 364:273-283. CrossRef Medline

Lenroot RK, Gogtay N, Greenstein DK, Wells EM, Wallace GL, Clasen LS, Blumenthal JD, Lerch J, Zijdenbos AP, Evans AC, Thompson PM, Giedd JN (2007) Sexual dimorphism of brain developmental trajectories during childhood and adolescence. Neuroimage 36:1065-1073. CrossRef Medline

Lentini E, Kasahara M, Arver S, Savic I (2013) Sex differences in the human brain and the impact of sex chromosomes and sex hormones. Cereb Cortex 23:2322-2336. CrossRef Medline

Lombardo MV, Ashwin E, Auyeung B, Chakrabarti B, Taylor K, Hackett G, Bullmore ET, Baron-Cohen S (2012) Fetal testosterone influences sexually dimorphic gray matter in the human brain. J Neurosci 32:674-680. CrossRef Medline

Manning SE, Davin CA, Barfield WD, Kotelchuck M, Clements K, Diop H, Osbahr T, Smith LA (2011) Early diagnoses of autism spectrum disorders in Massachusetts birth cohorts, 2001-2005. Pediatrics 127:10431051. CrossRef Medline

Martin DD, Schweizer R, Schwarze CP, Elmlinger MW, Ranke MB, Binder G (2004) The early dehydroepiandrosterone sulfate rise of adrenarche and the delay of pubarche indicate primary ovarian failure in Turner syndrome. J Clin Endocr Metab 89:1164-1168. CrossRef Medline

Marzelli MJ, Hoeft F, Hong DS, Reiss AL (2011) Neuroanatomical spatial patterns in Turner syndrome. Neuroimage 55:439-447. CrossRef Medline

Mazzocco MM (2006) The cognitive phenotype of Turner syndrome: specific learning disabilities. Int Congr Ser 1298:83-92. CrossRef Medline

McCarthy MM, Arnold AP (2011) Reframing sexual differentiation of the brain. Nat Neurosci 14:677-683. CrossRef Medline

Mendelsohn ME, Karas RH (2005) Molecular and cellular basis of cardiovascular gender differences. Science 308:1583-1587. CrossRef Medline

Modi DN, Sane S, Bhartiya D (2003) Accelerated germ cell apoptosis in sex chromosome aneuploid fetal human gonads. Mol Hum Reprod 9:219225. CrossRef Medline

Molko N, Cachia A, Riviere D, Mangin JF, Bruandet M, LeBihan D, Cohen L, Dehaene S (2004) Brain anatomy in Turner syndrome: evidence for impaired social and spatial-numerical networks. Cereb Cortex 14:840-850. CrossRef Medline

Murphy MM, Mazzocco MM, Gerner G, Henry AE (2006) Mathematics learning disability in girls with Turner syndrome or fragile $\mathrm{X}$ syndrome. Brain Cogn 61:195-210. CrossRef Medline

Neufang S, Specht K, Hausmann M, Güntürkün O, Herpertz-Dahlmann B, Fink GR, Konrad K (2009) Sex differences and the impact of steroid hormones on the developing human brain. Cereb Cortex 19:464-473. CrossRef Medline

Ngun TC, Ghahramani N, Sánchez FJ, Bocklandt S, Vilain E (2011) The genetics of sex differences in brain and behavior. Front Neuroendocrinol 32:227-246. CrossRef Medline

Nguyen TV, McCracken JT, Ducharme S, Cropp BF, Botteron KN, Evans AC, KaramaS (2013) Interactive Effects of dehydroepiandrosterone and testosterone on cortical thickness during early brain development. J Neurosci 33:10840-10848. CrossRef Medline

Nichols T, Brett M, Andersson J, Wager T, Poline JB (2005) Valid conjunction inference with the minimum statistic. Neuroimage 25:653-660. CrossRef Medline

Patwardhan AJ, Eliez S, Bender B, Linden MG, Reiss AL (2000) Brain morphology in Klinefelter syndrome: extra X chromosome and testosterone supplementation. Neurology 54:2218-2223. CrossRef Medline
Peper JS, Brouwer RM, Schnack HG, van Baal GC, van Leeuwen M, van den Berg SM, Delemarre-Van de Waal HA, Boomsma DI, Kahn RS, Hulshoff Pol HE (2009) Sex steroids and brain structure in pubertal boys and girls. Psychoneuroendocrinology 34:332-342. CrossRef Medline

Rae C, Joy P, Harasty J, Kemp A, Kuan S, Christodoulou J, Cowell CT, Coltheart M (2004) Enlarged temporal lobes in Turner syndrome: an X-chromosome effect? Cereb Cortex 14:156-164. CrossRef Medline

Rao E, Weiss B, Fukami M, Rump A, Niesler B, Mertz A, Muroya K, Binder G, Kirsch S, Winkelmann M, Nordsiek G, Heinrich U, Breuning MH, Ranke MB, Rosenthal A, Ogata T, Rappold GA (1997) Pseudoautosomal deletions encompassing a novel homeobox gene cause growth failure in idiopathic short stature and Turner syndrome. Nat Genet 16:54-63. CrossRef Medline

Rilea SL, Roskos-Ewoldsen B, Boles D (2004) Sex differences in spatial ability: a lateralization of function approach. Brain Cogn 56:332-343. CrossRef Medline

Ross JL, Roeltgen D, Kushner H, Wei F, Zinn AR (2000) The Turner syndrome-associated neurocognitive phenotype maps to distal Xp. Am J Hum Genet 67:672-681. CrossRef Medline

Ross JL, Samango-Sprouse C, Lahlou N, Kowal K, Elder FF, Zinn A (2005) Early androgen deficiency in infants and young boys with 47, XXY Klinefelter syndrome. Horm Res 64:39-45. CrossRef Medline

Russell HF, Wallis D, Mazzocco MM, Moshang T, Zackai E, Zinn AR, Ross JL, Muenke M (2006) Increased prevalence of ADHD in Turner syndrome with no evidence of imprinting effects. J Pediatr Psychol 31:945-955. CrossRef Medline

Sack AT, Kohler A, Bestmann S, Linden DE, Dechent P, Goebel R, Baudewig J (2007) Imaging the brain activity changes underlying impaired visuospatial judgments: simultaneous FMRI, TMS, and behavioral studies. Cereb Cortex 17:2841-2852. CrossRef Medline

Shen D, Liu D, Liu H, Clasen L, Giedd J, Davatzikos C (2004) Automated morphometric study of brain variation in XXY males. Neuroimage 23: 648-653. CrossRef Medline

Siegel C, Turtzo C, McCullough LD (2010) Sex differences in cerebral ischemia: possible molecular mechanisms. J Neurosci Res 88:2765-2774. CrossRef Medline

Tartaglia NR, Ayari N, Hutaff-Lee C, Boada R (2012) Attention-deficit hyperactivity disorder symptoms in children and adolescents with sex chromosome aneuploidy: XXY, XXX, XYY, and XXYY. J Dev Behav Pediatr 33:309-318. CrossRef Medline

Temple CM, Carney R (1996) Reading skills in children with Turner's syndrome: an analysis of hyperlexia. Cortex 32:335-345. CrossRef Medline

Vawter MP, Harvey PD, DeLisi LE (2007) Dysregulation of X-linked gene expression in Klinefelter's syndrome and association with verbal cognition. Am J Med Genet B Neuropsychiatr Genet 144B:728-734. CrossRef Medline

Voyer D, Voyer S, Bryden MP (1995) Magnitude of sex differences in spatial abilities: a meta-analysis and consideration of critical variables. Psychol Bull 117:250-270. CrossRef Medline

Weickert CS, Elashoff M, Richards AB, Sinclair D, Bahn S, Paabo S, Khaitovich P, Webster MJ (2009) Transcriptome analysis of male-female differences in prefrontal cortical development. Mol Psychiatry 14:558-561. CrossRef Medline

Wikström AM, Dunkel L, Wickman S, Norjavaara E, Ankarberg-Lindgren C, Raivio T (2006) Are adolescent boys with Klinefelter syndrome androgen deficient? A longitudinal study of Finnish 47, XXY boys. Pediatr Res 59:854-859. CrossRef Medline

Wilson JD, George FW, Griffin JE (1981) The hormonal control of sexual development. Science 211:1278-1284. CrossRef Medline

Yoshimasu K, Barbaresi WJ, Colligan RC, Killian JM, Voigt RG, Weaver AL, Katusic SK (2010) Gender, attention-deficit/hyperactivity disorder, and reading disability in a population-based birth cohort. Pediatrics 126: e788-795. CrossRef Medline 